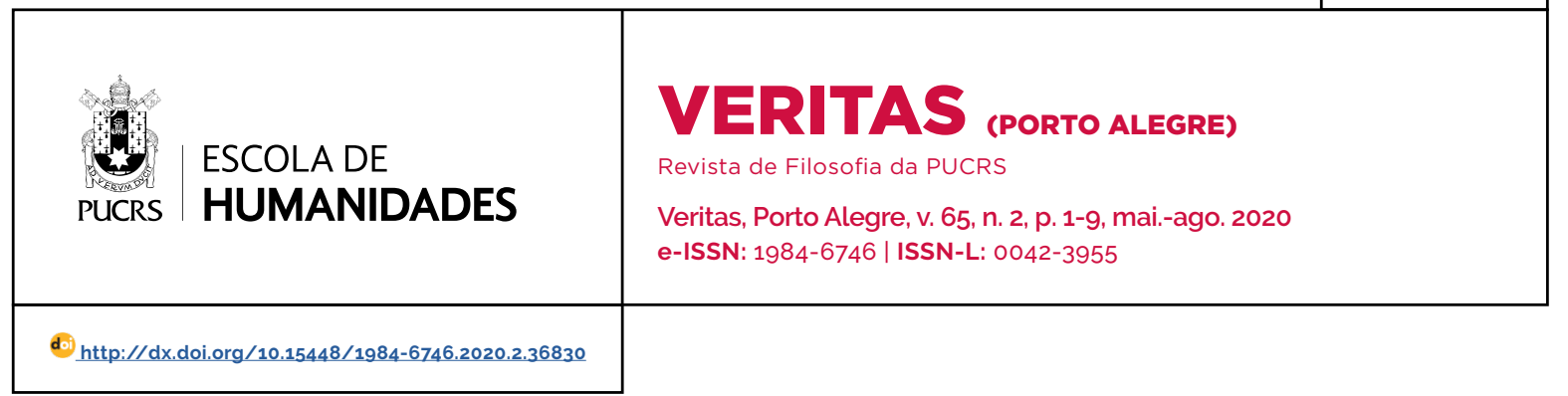

SEÇÃO: VARIA

\title{
O papel das emoções no processo de tomada de decisão moral diante de conflitos bioéticos
}

\author{
The role of emotions in the moral decision-making process in the face of bioethical conflicts \\ El papel de las emociones en el proceso de toma de decisiones morales frente a los \\ conflictos bioéticos.
}

\section{Caroline Izidoro Marim ${ }^{1}$ orcid.org/0000-0002-4554-3653 caroline.marim@gmail.com}

Recebido em: 13 jan. 2020. Aprovado em: 18 fev. 2020 Publicado em: 28 jul. 2020

\section{(c) (1)}

Artigo está licenciado sob forma de uma licença Creative Commons Atribuição 4.0 Internacional.
Resumo: O presente artigo tem por objetivo mostrar o papel crucial das emoções nas tomadas de decisões morais e sua contribuição na solução de conflitos bioéticos. Ao contrário da tese racional, as tomadas de decisão morais demandam a colaboração entre razão e emoção, ou nos termos dos estudos em Metaética, cognição e emoção. Por meio da análise da teoria de António Damásio, teses de filósofas morais feministas, como Kathryn Pyne Addelson e Martha Nussbaum, entre outras e pretendemos refutar as recorrentes teses bioéticas conservadoras cuja autoridade moral é erroneamente delegada exclusivamente à racionalidade em detrimento das emoções.

Palavras-chave: Tomada de decisão moral. Emoções. Marcadores-somáticos. Bioética.

Abstract: This paper aims to show the crucial role of emotions in moral decision-making and their contribution to the resolution of bioethical conflicts. Contrary to the rational thesis, moral decision-making demands the collaboration between reason and emotion, or in terms of studies in metaethics, cognition and emotion. Through the analysis of António Damásio's theory, theses from feminist moral philosophers such as Kathryn Pyne Addelson and Martha Nussbaum, among others, we intend to refute the recurrent conservative bioethical theses whose moral authority is erroneously delegated to rationality over emotions.

Keywords: Moral decision making. Emotions. Somatic markers. Bioethics.

Resumen: Este artículo tiene como objetivo mostrar el papel crucial de las emociones en la toma de decisiones morales y su contribución a la solución de conflictos bioéticos. Contrariamente a la tesis racional, la toma de decisiones morales requiere la colaboración entre la razón y la emoción, o en términos de estudios en Metaética, cognición y emoción. Al analizar la teoria de António Damásio, las tesis de filósofas morales feministas, como Kathryn Pyne Addelson y Martha Nussbaum, entre otras, pretendemos refutar las tesis bioéticas conservadoras recurrentes cuya autoridad moral se delega erróneamente en la racionalidad a expensas de las emociones.

Palabras clave: Toma de decisiones morales. Emociones. Marcadores somáticos. Bioética.

\section{Introdução}

Poucos campos foram tão trabalhados e discutidos nas Universidades e instituições de saúde nos últimos anos como os debates em bioética. No entanto, apesar da Bioética se caracterizar como um campo aplicado da ética, cuja principal preocupação é a aplicação de princípios extraídos 
da ética normativa às experiências concretas da vida, do nosso ponto de vista este preceito é pouco atendido nos debates brasileiros. Tal cenário ético, político e jurídico nos revela uma sociedade extremamente conservadora e pouco reflexiva fundada em principios universalistas conservadores ultrapassados, pouco eficazes para solução dos conflitos práticos.

A bioética é repleta de casos conflituosos, que em sua maioria compreende decisões extremas, como por exemplo decidir entre manter um tratamento e retirar o mesmo tratamento de pacientes que estão inconscientes, principalmente quando não há garantias de resultado. Os principios bioéticos utilitarista e preferencialista sugerem que essas duas ações são eticamente equivalentes. O precedente legal mostra que a lei os trata como ações comparáveis. No entanto, tanto os profissionais de saúde quanto as famílias dizem que as duas ações são muito diferentes. Outro exemplo é a diferença entre retirar o suporte de vida em um paciente que está acordado e alerta em comparação com retirar o suporte de vida em um paciente que está inconsciente. Se o diagnóstico e o prognóstico forem os mesmos, o fato da consciência não altera a legalidade ou a moralidade da ação. Mas os participantes do processo decisório se sentem muito diferentes diante de cada caso.

O dilema nestes casos está relacionado a dois tipos de desacordo morais. Primeiro, um desacordo moral de ordem interna, que pode ser tanto por força ou prioridade da aceitação de padrões morais; limitações dos padrões morais mutuamente acordados; a forma na aplicabilidade de certos padrões morais. Um exemplo pode ser o caso em que duas médicas concordam sobre o princípio moral de contar a verdade ao paciente, contudo a médica A acredita que o diagnóstico deve ser dado mesmo que seja pessimista, enquanto a médica $B$ acredita que diagnósticos pessimistas devem ser evitados para evitar sofrimento. Segundo os desacordos morais radicais, que podem ser parciais ou totais. Os parciais dizem respeito a situações nas quais partes contrárias podem concordar com alguns critérios de relevância, mas não completamente. Como exemplo, casos nos quais médicas ou enfermeiros alegam ser moralmente errado aplicar injeções em pacientes terminais, porém consideram correto deixar a natureza tomar seu curso natural. Os casos de desacordos morais radicais totais são aqueles nos quais nenhuma das partes envolvidas concordam com quaisquer critérios de relevância e não compartilham quaisquer principios morais básicos. Megan-Jane Jonhstone apresenta em seu livro Bioethics: a nursing perspective (2009, p. 107), um exemplo no qual dois enfermeiros discordam sobre o transplante de órgãos. O enfermeiro A acredita que o retirar órgãos de pessoas que ainda não estão completamente mortas se caracteriza como assassinato. Este enfermeiro não considera a morte cerebral como indicativo de morte. Enquanto, o enfermeiro B rejeita a santidade da vida e concorda com o transplante por acreditar que a pessoa já está morta quando é realizada a retirada do órgão.

Quando encontramos um dilema moral, o principal problema não está nos princípios morais que escolhemos, mas qual a melhor maneira de fazer o que decidimos; ou seja, qual a melhor forma de resolver o problema, ou os problemas que encontramos. Constantemente, quando nos deparamos com um problema moral incomum a principal pergunta que surge é se devo agir de acordo com o que decidi?

Nesse processo de análise e considerações frente a dilemas morais alguns processos podem ser utilizados para as tomadas de decisão. Johnstone nos apresenta um processo de tomada de decisão em cinco etapas que se tornou universalmente associado ao processo de enfermagem. Esse processo de cinco etapas exige que os tomadores de decisão reais:

1. Avaliem a situação, incluindo fazer uma avaliação diligente dos fatos relevantes do assunto e dos valores operacionais na situação em questão;

2. Diagnosticar ou identificar o problema moral em questão;

3. Estabelecer metas morais e planejar um curso de ação moral apropriado para abordar os problemas morais identificados;

4. Implementar o plano de ação moral;

5. Avaliar os resultados morais da ação implementada (JOHNSTONE, 2009, p. 116). 
A decisão moral normalmente é realizada por um individuo (enfermeiro, médica, paciente, familiares) ou por uma entidade coletiva (equipe de assistência médica, um grupo de partes interessadas ou um comitê). Em todos os casos, os tomadores de decisão precisam tomar um cuidado particular em garantir que uma avaliação cuidadosa seja feita dos fatos relevantes do caso, bem como dos valores que estão operando no contexto fornecido em questão. Isto principalmente porque fatos e valores podem exercer uma influência considerável sobre a posição do outro e, como consequência, podem até levar a profundas mudanças em nossas concepções sobre o caso em questão e a decisão moral que tomaremos.

Entretanto, o ponto crucial ao usar um processo sistemático de tomada de decisão moral é considerar que as deliberações, durante cada uma das etapas identificadas, envolvem apelos não somente a razão, mas também a emoção e a intuição, ${ }^{2}$ sendo que cada uma delas, por sua vez, é informada ou marcada por experiências de vida. Embora pareça uma tarefa fácil, as disputas morais nem sempre contam com o importante papel e relevância na integração entre razão, emoção, intuição e experiência de vida na tomada de decisões morais, principalmente casos nos quais podemos dizer grosseiramente que as emoções nos puxam em uma direção e a razão em outra.

Este é o cenário que pretendemos rever. Cenário no qual teses bioéticas conservadoras financiam e fortalecem a supremacia da função da racionalidade e da "pura razão prática" nas tomadas de decisão morais em detrimento do papel que as emoções, as intuições e experiências de vida desempenham na moralidade. Assim, nosso objetivo é mostrar como estas teses têm sido refutadas tanto por filósofos morais (particularmente filosofias feministas) e biomédicos, como confirmadas por alguns trabalhos recentes em neuroética.

\section{A contribuição do estudo das emoções para a bioética}

A realização e participação ao IV Colóquio Internacional em Bioética na PUCRS (2019) realizado conjuntamente ao II Colóquio Emoções tornou evidente a urgência e extrema pertinência das pesquisas sobre as emoções para o avanço e sofisticação dos debates em bioética. Afinal, apesar dos grandes avanços nos debates em bioética, temas ainda iniciais como o aborto, eutanásia, ética animal e ambiental ainda se deparam com inúmeras resistências práticas e teóricas que podem encontrar novos caminhos com a contribuição das pesquisas sobre as emoções.

Apesar de ser um tema cada vez mais presente nos debates éticos, a menção ao papel das emoções nas teorias e debates bioéticos ainda são escassas e pouco comentadas confirmando a supremacia de um modelo de racionalidade problemático e extremamente conservador. Como Martha Nussbaum (2001) aponta, as emoções são como irrupções do pensamento. São elas que conduzem e estruturam os juizos morais no enfrentamento e aplicação das teorias normativas em diferentes tipos de conflitos. As emoções são o próprio pensamento; são os guias sofisticados da natureza humana na e para a ação, tanto avaliativa, cognitiva como motivacional e, tem papel fundamental nas tomadas de decisão. São elas que possibilitam as correlações mais criativas que fazemos do e no mundo; disparam não apenas reações automáticas em nosso organismo que são fundamentais para a nossa sobrevivência, mas também são o resultado de um sistema normativo sofisticado que nossa evolução nos habilitou através da linguagem, uma sutil linguagem que não se reduz as palavras ou a expressão das emoções; são fundamentais para nosso equilibrio homeostático como defende António Damásio (2011) e também para o equilibrio em todas as relações humanas e nossas relações com não humanos.

Não é um acaso que as emoções foram desprezadas ou associadas pela tradição filosófica e científica como um componente de nossa

\footnotetext{
2 Neste artigo escolhe me concentrar apenas no papel da emoção fazendo apenas menção ao papel da intuição e experiência de vida. Para saber mais consultar: JOHNSTONE, 2009.
} 
animalidade menos valoroso em contraposição à razão. Algumas feministas como Sara Ahmed (2015) revelam que a relação entre ser emocional, feminino, mais próximo da condição animal e mais primitiva é fruto de teorias misóginas e especistas que ainda são pouco refutadas. Por isto não é um acaso que cada vez mais filósofas morais e epistemólogas refutem a neutralidade, imparcialidade e universalidade tradicionalmente defendidas pelos cânones filosóficos tradicionais.

Esse preconceito contra as emoções deve-se a tradicional hierarquia entre emoção e razão consolidada principalmente por muitas teorias filosóficas que insistimos em ensinar a nossos alunos e alunas. As emoções não devem ser controladas, mas aprimoradas. São as emoções que orientam nossas ações. Somos seres morais por conta de sermos dotados de emoção e não de razão. Não somos máquinas ou sistema metafísicos destituidos de corpo. Somos sistemas complexos da natureza.

Todos, ou pelo menos grande parte dos problemas éticos e bioéticos de algum modo tem como base a compreensão de um sujeito moral que é guiado mais pelas emoções do que por uma idealização dos poderes da racionalidade. O cenário sobre a compreensão do papel das emoções no comportamento e nos juizos humanos tem mudado no mundo desde a década de 50 do século passado quando passaram a ocupar um lugar de destaque nos debates da filosofia da mente, porém mais recentemente, por conta das inúmeras pesquisas em neurociência este cenário tem se sofisticado cada vez mais. Podemos hoje compreender melhor o que é uma emoção, como ela funciona, sua abrangência e qual a sua influência em nossa fisiologia, comportamento e funções cognitivas. Recentemente surgiu uma nova área, a Neurociência afetiva para dar conta das explicações sobre o funcionamento dos juizos morais e sua base neural, isto é: Qual é a base neural da cognição moral? Ou, como funciona nosso mecanismo de recompensas para compreender melhor o funcionamento do desejo levando em conta a função da dopamina em nosso organismo, por exemplo.

Muitos estudos têm sido feitos sobre percepção e julgamento moral, ou mesmo estudos sobre estresse e resiliência e aprimoramento emocional tem como base o estudo das emoções e contribuem para o desenvolvimento de remédios que aprimoram nossas capacidades cognitivas. Porém, o verdadeiro aprimoramento humano deve ser o emocional, pois enquanto continuarmos a reforçar a ultrapassada separação entre razão e emoção e hipervalorizá-la não teremos avançado moralmente. O mesmo limite que a Inteligência Artificial (IA) se depara hoje. A limitação das máquinas é a criatividade como apontou Rabino Fishel Szlajen no "IV Colóquio Internacional de Bioética" em seu artigo "Inteligencia Artificial y Transhumanismo: falacias del humano exacerbado y desfondado en la tecnología:

\begin{abstract}
A denominada inteligência artificial não é um dado grande, ou as diferentes formas de envasar o esférico de milhões de pessoas usando algoritmos que também são usados por pessoas, mas não há algo em si mesmo. Você está calculando, não há inteligência e muito menos consideração. Em algum lugar, a singularidade não existe na imaginação, e os processos biológicos e culturais foram graduais e constituídos por casos recorrentes (OLIVEIRA et al., 2019, p. 54, tradução nossa). ${ }^{3}$
\end{abstract}

As máquinas são limitadas a algoritmos que não dão conta da solução de problemas que os seres humanos resolvem com as emoções. São as emoções as responsáveis por sofisticar nossa existência. Tanto como uma máquina, os seres humanos que sofreram lesões no córtex préfrontal, como defende Damásio são incapazes de se relacionar socialmente, apesar das capacidades de raciocínio matemático intacta.

Sabemos hoje que várias estruturas cerebrais têm um papel chave para controlar as condutas sociais como aponta Butman e Allegri:

\footnotetext{
3 Do original: La denominada inteligencia artificial no es sino una big data, o diferentes formas de envasar el esfuerzo de millones de personas mediante algoritmos hechos también por personas, pero no es algo en sí mismo. Y esto es cálculo, no es inteligencia y mucho menos pensamiento. En tercer lugar, la singularidad no existe sino en la imaginación, ya que los procesos biológicos y culturales han sido graduales y constituidos por puntuales casos repentinos revolucionarios sintetizados con largos periodos de equilibrio estático en dichos cambios.
} 
O córtex pré-frontal ventromedial, a amígdala, o córtex somatosensorial direito e a insula. $O$ córtex pré-frontal ventromedial está comprometido com o raciocínio social e com a tomada de decisões; a amigdala com o julgamento social de faces; o córtex somatosensorial direito, com a empatia e com a simulação; enquanto a insula, com a resposta autonômica (2001, p. 275).

A cognição social é o processo que orienta condutas frente a outros indivíduos da mesma espécie. Podemos cada vez mais inferir que temos sido governados por psicopatas, pessoas inábeis emocionalmente, mas dotadas de capacidades de cálculo e estratégia sofisticadas. ${ }^{4}$ Há um grave erro em acharmos que o problema é de ordem racional e não emocional. Psicopatas e sociopatas são dotados de habilidades racionais exemplares, porém tem comportamentos moralmente danosos. O problema não é de cálculo, mas os danos nas conexões e/ou regiões do cérebro vitais para um bom desempenho emocional.

Máquinas têm dificuldade em compreender valores humanos, algoritmos de aprendizado de máquina (ML) já podem reconhecer padrões muito melhor do que os humanos para os quais trabalham. Isso lhes permite gerar previsões e tomar decisões em diversas situações de alto risco. No entanto, para que os sistemas de ML sejam realmente bem-sucedidos, eles precisam entender os valores humanos. Mais precisamente, eles precisam ser capazes de avaliar nossos desejos e demandas concorrentes, entender quais resultados mais valorizamos e agir em conformidade. Como resultado, esses métodos são insuficientes no que diz respeito a futuros sistemas $\mathrm{AGI}^{5}$, que agem de forma autônoma e, portanto, precisarão de uma compreensão mais sofisticada de quando os valores humanos mudam e mudam. Quando se trata de incorporar valores, Sotala (2015, p.1) observa que o problema se resume em como os agentes inteligentes tomam decisões. ${ }^{6}$

\section{Emoções e tomadas de decisões morais}

A principais críticas que filósofas morais feministas, entre elas Moira Gatens e Kathryn Addelson, têm feito à defesa da razão como a autoridade suprema que governa a moralidade são: (1) a razão não possui valor neutro e não é mais objetiva do que a subjetividade que a prefere e valoriza (GATENS, 1986, p. 25); (2) é um guia confiável para tomar decisões e ações morais sólidas (ADDELSON, 1994, p. 134). Elas questionam principalmente porque a razão deve ser considerada como tendo mais autoridade no pensamento moral e na tomada de decisões do que as emoções morais, como por exemplo, empatia, compaixão, simpatia, bondade, simpatia ou carinho. Do mesmo modo, cientistas biomédicos também defendem que a tomada de decisão moral sólida e eficaz requer um apelo à emoção e à intuição, bem como à razão.

Até mesmo na tradição nem todos concordam que a razão é a autoridade suprema que governa a moralidade ou fornece um guia mais confiável para os processos decisórios e as ações morais do que outras faculdades humanas, como a emoção ou a intuição. O mais conhecido deles é David Hume (1711-76), que rejeita a razão como a última autoridade moral e a defende como nada mais do que "a comparação de ideias e descoberta de suas relações" (HUME, 2009, p. 466). Ele considerava a razão como 'impotente' e perfeitamente inerte em domínios morais, nunca podendo prevalecer ou produzir qualquer ação ou afeto (HUME, 2009, p. 458). O único poder que a razão tem, na estrutura conceitual de Hume, é na formação de crenças - e, mesmo assim, crenças não são confiáveis para levar alguém a ação, ao menos que sejam relevantes para a satisfação de alguma paixão, desejo ou necessidade.

\footnotetext{
4 Apesar de ainda haver poucas pesquisas clínicas e principalmente atualizadas sobre o tema psicopatia e política alguns estudos como o realizado por Stephen Porter e Michael Woodworth no artigo "Psychopaty and Agression" (2006. p. 483) revelam que: "It has been long recognised that psychopaths expends much time and energy in exploiting others. With little empathy or remorse, they have few inhibitions against using other people for material gain, drugs, sex, or power. [...] Some may even become cult leaders, corrupt politicians, or successful corporate leaders. [...] In fact, most antissocial behavior by "white colar" psychopaths may be characterized in this way". Consultar também: BABIAK, 2006

5 Conhecida também como "IA forte" (Strong AI) ou "IA nivel humano" (Human Level AI), refere-se a um computador que é tão inteligente quanto um humano, em um leque enorme de habilidades (e não apenas em uma) - é uma máquina com a mesma capacidade intelectual de um ser humano, podendo realizar qualquer atividade inteligente que o homem domine.

6 Sobre o tema agentes inteligentes e tomadas de decisão consultar WALLACH et al., 2010.
} 
Em essência, Hume entende a moralidade mais como uma questão de sentir do que julgar, como podemos conferir na seguinte passagem:

[...] se a virtude e o vício são determinados pelo prazer e a dor, estas qualidades devem, em todos os casos, ter origem nas sensações; e, por conseguinte, um objeto, animado ou inanimado, racional ou irracional, pode tornar-se moralmente bom ou mal, contando que possam despertar uma satisfação ou um mal-estar (HUME, 2009, p. 472)

Sentir prazer e dor são as fontes da moralidade e, portanto, os sentimentos ${ }^{7}$ constituem os processos decisórios sendo responsáveis por regular nossa conduta e comportamento (HUME, 2009, p. 469).

Hume não está sozinho em sua crítica da razão como guia moral de ação. A supremacia da racionalidade e a "pura razão prática" nas tomadas de decisão morais tem sido criticada tanto por filósofos morais (particularmente filosofias feministas) como por cientistas biomédicos. Resumindo, Hume descreve a moralidade a partir das sensações de prazer (emoções morais) como forma de distinguir o que é virtuoso, e as sensações de dor e inquietação como forma de distinguir o que é cruel.

O principal problema dos defensores de teorias que se pautam em uma superioridade da razão é principalmente por não levarem em consideração o fato de que, antes mesmo de construir suas teorias e defendê-las, suas mentes já haviam decidido por um caminho se mostrando como pouco permeáveis a outras perspectivas. A falta de critérios irrefutáveis para convencer seus oponentes inevitavelmente vê o que deveria ser um debate frutifero e vivo reduzido a nada mais do que uma campo de batalha caracterizado por asserções dogmáticas e contra-asserções. $O$ mais interessante é que inúmeras vezes alguns oponentes teóricos se cansam do infrutifero debate e simplesmente desistem escolhendo o silêncio, afinal a falha na escuta é principalmente uma característica dos ignorantes dotados de pouca inteligência emocional.

Na direção de Hume, Damásio propõe a tese do primado das emoções nos processos decisórios, pois o ato de decidir não trata apenas de uma questão de saber ou julgar, mas, sobretudo, de sentir. Suas pesquisas mostram que a dimensão emotiva expressa em termos neurocientificos acontece tanto na estrutura subcortical como na estrutura cortical, de modo que "os sentimentos ${ }^{8}$ são tão cognitivos como qualquer outra imagem perceptual e tão dependentes do córtex cerebral como qualquer outra imagem" (DAMÁSIO, 2006, p. 190).

No seu já conhecido livro O Erro de Descartes (2006), Damásio aponta o papel crucial das emoções nas tomadas de decisões morais. Ele sustenta que tomadas de decisões integradas são mais bem-sucedidas na solução de conflitos. Isto por conta de que marcas somáticas, tais como emoções viscerais ajudam a melhorar tanto a precisão quanto a eficiência do processo de tomada de decisão. Assim, ao contrário da tese racional as tomadas de decisão morais exigem a colaboração entre razão e emoção.

Damásio foi um dos primeiros neurocientistas a apontar que "há uma significante interação dos sistemas subjacentes ao processo de emoção, sentimento, razão e tomada de decisão, onde os centros emocionais do cérebro são afetados adversamente, assim como a capacidade de uma pessoa de fazer importantes julgamentos morais que sustentam a vida" (DAMÁSIO, 2006, p. 44). Sua conclusão deve-se a inúmeras pesquisas realizadas em pacientes que sofreram lesões cerebrais que revelaram que o declinio das emoções pode resultar em graves falhas nas tomadas de decisão. Lesões no córtex pré-frontal ${ }^{9}$

\footnotetext{
7 Há uma discordância sobre o uso e sentido dos termos emoções e sentimentos em diversas teorias das emoções, por isto escolho manter a tradução de feeling como sentimento e emoção apenas quando se utiliza a palavra emotion, sem me preocupar nesta situação com o funcionamento que representa cada uma delas.

8 António Damásio defende que as emoções são um conjunto de respostas quimicas e neuronais que formam um padrão distintivo. Ele a definiu como "marcador somático", uma marca emocional que nos faz reagir e que nos influencia na hora de mostrar certas condutas ou realizar um determinado tipo de decisões. As emoções pertencem ao corpo, e os sentimentos têm uma relação mais profunda com os pensamentos, com a mente (DAMÁSIO, 2006, p. 43).

9 Para corroborar o primado das emoções nos processos decisórios, Damásio apresenta os casos de Phineas Gage e Elliot, casos de individuos que tiveram regiões do córtex pré-frontal comprometidas e que, consequentemente, diminuiram, mormente, a capacidade de tomar decisões acertadas e tidas comumente como razoáveis (DAMÁSIO, 2006, p. 35).
} 
podem causar não apenas danos na capacidade de sentir emoções, mas acompanhar graves danos às relações pessoais e interpessoais humanas.

Damásio constata que apesar de ter as suas capacidades cognitivas intactas, adotar uma abordagem puramente racionalista e vinculada a regras para a tomada de decisões morais pode ser um caminho duvidoso, pois a visão de uma "superrazão" é nada mais do que uma visão do senso comum, que pressupõe ficarmos orgulhosos e felizes com as teorias de Platão, Descartes e Kant quando tomamos nossas melhores decisões. Esta crença acompanha a ideia de que a lógica formal, por si só, nos leva à melhor solução disponível para qualquer problema e, para que a concepção racionalista obtenha os melhores resultados deve se manter distante ou mesmo fora das emoções. Isto é, o processamento racional deve ser livre de qualquer paixão.

Entretanto, Damásio afirma que se essa estratégia for a única disponivel, a racionalidade, conforme descrito acima, não funcionará, pois:

Na melhor das hipóteses, sua decisão levará um tempo excessivamente longo, muito mais do que aceitável, se você quiser fazer algo naquele dia. Na pior das hipóteses, você pode nem mesmo tomar uma decisão porque se perderá nos desvios de seus cálculos. (...) Você perderá a noção. Atenção e memória de trabalho têm capacidade limitada. No final, se sua mente normalmente opera apenas com cálculos puramente racionais, você pode escolher incorretamente e viver para se arrepender do erro, ou simplesmente desistir de tentar. frustrado (DAMÁSIO, 2006, p. 202).

Ao contrário dessa situação, tomadores de decisão integrados se sairão muito melhor, exatamente por conta de suas marcas somáticas, emoções viscerais que nos ajudam a melhorar tanto a precisão como a eficiência do processo de tomada de decisão. Damásio explica:

O marcador-somático concentra a atenção no resultado negativo ao qual uma determinada ação pode levar e funciona como um sinal de alarme automatizado que diz: cuidado com o perigo à frente se você escolher a opção que leva a esse resultado. O sinal pode levar você a rejeitar, imediatamente, o curso de ação negativo e, assim, fazer você escolher entre outras alternativas. O sinal automatizado protege você contra perdas futuras, sem mais delongas, e permite que você escolha entre menos alternativas. Ainda há espaço para o uso de uma análise de custo/benefício e competência dedutiva adequada, mas somente após a etapa automatizada reduzir drasticamente o número de opções (DAMÁSIO, 2006, p. 173).

Damásio contrapõe-se à intuição de William James de que a dimensão somatossensorial apenas serviria com um palco para o protagonismo das emoções, o que tornaria o corpo um mero coadjuvante dos processos psicológicos. Ele defende que o cérebro não é um autômato que funciona independente do corpo e, "(...) o cérebro não prevê os estados do corpo com rigor algoritmico, mas sim que o cérebro fica aguardando que o corpo the comunique o que realmente sucedeu" (DAMÁSIO, 2006, p. 189). O corpo marca emoções que influenciam nos nossos processos decisórios confirmando que não há uma racionalidade pura nos processos decisórios. Na verdade, "a mente não está vazia no começo do processo de raciocínio. Pelo contrário, encontra-se repleta de um repertório variado de imagens" (DAMÁSIO, 2006, p. 189).

Marcadores-somáticos são registros ou a marca emocional de nossas experiências pessoais ou resultado de transmissão cultural, como padrões éticos ou normas e punições sobre o certo e o errado. Tais marcas ficam armazenados no sistema neural dos córtices pré-frontais formando a partir daí imagens que constituem nossos pensamentos. No momento de uma tomada de decisão, os repertórios de estímulos que foram armazenados no cérebro pelos marcadores-somáticos são os primeiros a serem ativados, antecipando assim o profuso e minucioso cálculo racional da razão.

Mais recentemente, em seu $A$ estranha ordem das coisas: as origens biológicas dos sentimentos e da cultura (2018), Damásio recorre às emoções para explicar a consciência e as culturas humanas e em E O Cérebro Criou O Homem (2011), no qual apresenta sua tese sobre a relação mente-selfcorpo-cérebro, defendendo as emoções, como marcadores somáticos que desempenham a função da separação entre os conteúdos que são do self e os que não são (DAMÁSIO, 2011, p. 15). 


\section{A conciliação de diferentes perspectivas}

Como apontamos no início, um dos principais problemas que encontramos hoje é a aplicação das teorias éticas a circunstâncias concretas da vida. Este problema deve-se pela maneira que tratamos as questões morais, principalmente como defendemos pela ausência ou desvalorização do papel das emoções nas tomadas de decisão. A perspectiva de Damásio oferece um sistema somatossensório que compreende as tomadas de decisões morais como um processo integrado que favorece um diálogo cooperativo, mais do que competitivo. Porém, como podemos lidar com desacordos e disputas morais na prática?

Problemas e desacordos morais constituem um aspecto inevitável tanto de nossa vida pessoal como profissional. Esses conflitos acontecem, como aponta Johnstone porque

- diferentes indivíduos podem interpretar a mesma evidência e tirar conclusões bastante diferentes, mas razoáveis, dessa evidência;

- a evidência por si mesma pode ser contraditória, levando pessoas razoáveis a tirar conclusões razoavelmente diferentes;

- mesmo quando os indivíduos concordam sobre quais são os fatos ou considerações relevantes de um determinado assunto, eles podem, no entanto, discordar razoavelmente sobre os pesos que devem ser dados aos fatos e considerações, e chegar a conclusões bem diferentes (por exemplo, o debate sobre a permissibilidade moral) $\mathrm{O}$ aborto e a eutanásia se baseiam mais em discordâncias sobre os pesos de princípios morais relevantes do que sobre a aplicabilidade dos princípios morais per se:

- conceitos morais são frequentemente ambiguos e abertos a uma variedade de interpretações; individuos podem fazer diferentes interpretações razoáveis destes que, por sua vez, podem levar a diferentes conclusões (JOHNSTONE, 2009, p. 124, tradução nossa). ${ }^{10}$

Portanto, não podemos assegurar que exista um critério neutro para determinar uma visão razoável de mundo e um modo de vida que seja superior em todos os aspectos aos outros.
Tal como defende a epistemóloga social Donna Haraway (2008), a ciência e outras formas de saber são compostas de narrativas situadas, isto é de diferentes perspectivas sobre a compreensão de um fenômeno. Haraway não reconhece nenhuma diferença epistemológica entre ciência e ficção cientíica, ambas são histórias, diferindo apenas em características do estilo narrativo. Escreve Haraway: "A prática científica pode ser considerada um tipo de prática de contar histórias", pois "Os fatos em si são tipos de histórias" (HARAWAY, 2008, p. 3-4). Sendo assim, ao narrarmos histórias pessoais e profissionais desconstruimos as narrativas da normalidade que produzem cada vez mais exclusão, tornando incerto mais uma vez, o que pode um corpo, porém aumentando suas ressonâncias e cumplicidades.

\section{Considerações finais}

Um poderoso e elucidativo debate bioético, não é aquele que tenta nos convencer sobre a universalidade e suficiência de seus princípios, mas aquele que envolve cooperação e onde as pessoas tenham tempo e possam ter tempo para dialogar, para realmente ouvir o ponto de vista de outras pessoas, e, assim, dar reconhecimento aos outros a partir de uma escuta atenta, de modo a negociar acordos criativos ao invés de atitudes claras de controle, por um lado, ou de receptividade extrema ou total, por outro.

Tudo isto depende de uma capacidade sofisticada de integrar razão, emoção, intuição e experiência de vida. A tomada de decisão moral pede a integração das emoções à razão, mas também exige uma criativa imaginação moral - isto é, uma capacidade de refletir e imaginar possiveis "futuros" morais (opções) e soluções para problemas, e possiveis maneiras de processá-las, mesmo em situações hostis a considerações morais e de que maneira também envolvem um "impasse". Pode não parecer uma tarefa fácil e

\footnotetext{
10 Do original: [...] different individuals can interpret the same evidence differently and draw quite different yet reasonable conclusions from that evidence; the evidence itself may be contradictory, leading reasonable people to draw reasonably different conclusions; even when individuals agree about what the relevant facts or considerations of a given matter are, they may nevertheless reasonably disagree about the weightings that should be given to the facts and considerations, and arrive at quite different conclusions (e.g. the debate about the moral permissibility of abortion and euthanasia rests more on disagreement about the weightings of relevant moral principles than about the applicability of the moral principles per se); moral concepts are often ambiguous and open to a variety of interpretations; individuals may make different though reasonable conclusions.
} 
tampouco simples, porém, é sem dúvida um modo mais generoso e cuidadoso em enfrentar dilemas morais que dizem respeito à vida.

\section{Referências}

ADDELSON, Kathryn Pyne. Moral Passages: Toward a Collectivist Moral Theory. Routledge, 1994.

AHMED, Sara. The Cultural Politics of emotion. New York: Routledge, 2015.

BABIAK, P. Psychopathic manipulation at work. In: GACONO, C. B. (ed.). The Clnical and forensic as sessment of psychopathy: A practioner's guide. Mahwah: Erlbaum, 2006. p. 287-311.

BUTMAN, Judith; ALLEGRI, Ricardo. A Cognição Social e o Córtex Cerebral. Revista Psicologia: Reflexão e Crítica, [s. l.], v. 14, n. 2, 2001, p. 275-279. DOI: https://doi. org/10.1590/S0102-79722001000200003.

DAMÁSIO, António R. O erro de Descartes: emoção, razão e o cérebro humano. 2. ed. Tradução Dora Vicente e Georgina Segurado. São Paulo: Companhia das Letras, 2006.

DAMÁSIO. A estranha ordem das coisas: as origens biológicas dos sentimentos e da cultura. São Paulo: Companhia das Letras, 2018.

DAMÁSIO. E O Cérebro Criou O Homem. São Paulo: Companhia das Letras, 2011.

GATENS, Moira. Rousseau and Wollstonecraft: Nature vs. reason. Australasian Journal of Philosophy, [s. L.], n. 64. p. 1-15, jun. 1986. Supl. Women and philosophy. DOI: https://doi.org/10.1080/00048402.1986.9755421.

HARAWAY, Donna. Primate visions: gender, race, and nature in the world of modern science. New York: Routledge, 1989.

HARAWAY. Saberes Localizados: a questão da ciência para o feminismo e o privilégio da perspectiva parcial. Tradução de Mariza Corrêa. Cadernos pagu, [s. l.], v. 5 , p. 7-41, 1995.

HARAWAY. Simians, Cyborgs, and Women: The Reinvention of Nature. New York/London: Routledge, 1991.

HUME, David. Tratado da natureza humana: uma tentativa de introduzir o método experimental de raciocínio nos assuntos morais. Tradução de Débora Danowski. São Paulo: Editora Unesp, 2009.

JOHNSTONE, Megan-Jane. Bioethics: a nursing perspective. Australia: Elsevir, 2009.

NUSSBAUM, Martha. Emotions as upheavals of thought: the intelligence of emotions. Chicago: Cambridge University Press, 2001.DOI: https://doi.org/10.1017/ CBO9780511840715.

PORTER, Stephen; WOODWORTH, Michael. Psychopaty and Agression. Handbook of psychopathy: Clinical and applied issues, [s. l.], p. 481-494, 2006.
SOTALA, Kaj; YAMPOLSKIY, Roman V. Responses to Catastrofic AGI Risk: A Survey. Physica Scripta, Is. l.], n. 90, 2015. DOI: https://doi.org/10.1088/00318949/90/1/018001.

SZLAJEN, Rabino Fishel. Inteligencia Artificial y Transhumanismo: falacias del humano exacerbado y desfondado en la tecnología. In: OLIVEIRA, Nythamar; MARIM, Caroline; TASCHEN, Jair. Bioética, Neuroética e Emoções. Porto Alegre: Editora Fenix, 2019. DOI: https:// doi.org/10.36592/978-65-81110-11-6-03.

WALLACH, W.; FRANKLIN, S.; ALLEN, C. A conceptual and computational model of moral decision making in human and artificial agents.Topics Cognitive Science, p. 454-85, 2010. DOl: https://doi.org/10.1111/j. 1756-8765.2010.01095.x.

\section{Caroline Izidoro Marim}

Doutora em Filosofia pela Universidade Federal do Rio de Janeiro (UFRJ, Rio de Janeiro, RJ, Brasil), professora colaboradora da Pontificia Universidade Católica do Rio Grande do Sul (PUCRS, Porto Alegre, RS, Brasil). Pós-doutoranda PNPD/CAPES/PUCRS. Coordenadora do Grupo de Pesquisa Epistemologias, narrativas e politicas afetivas feministas CNPq/PUCRS.

\section{Endereço para correspondência}

Caroline Izidoro Marim

Pontificia Universidade Católica do Rio Grande do Sul Av. Ipiranga, 6681, Prédio 8, $4^{\circ}$ Andar

Partenon, 90619900

Porto Alegre, RS, Brasil 